\title{
Dermatoscopy and Reflective Confocal Microscopy for Facial Seborrheic Keratosis, Verruca Plana, and Nevus Pigmentosus
}

\author{
Quansheng $\mathrm{Lu}^{1,2}$, Shan Wang ${ }^{3}$, Tong $\mathrm{Wu}^{1}$ and Guan Jiang ${ }^{1}$ \\ ${ }^{1}$ Department of Dermatology, Affiliated Hospital of Xuzhou Medical University, Xuzhou, China \\ ${ }^{2}$ Department of Dermatology, The People's Hospital of Jiawang District of Xuzhou, Xuzhou, China \\ ${ }^{3}$ Department of Gastroenterology, Affiliated Hospital of Xuzhou Medical University, Xuzhou, China
}

\begin{abstract}
Objective: To describe the features of facial seborrheic keratosis, verruca plana, and nevus pigmentosus by dermatoscopy and reflective confocal microscope (RCM).

Study Design: Cross-sectional observational study.

Place and Duration of Study: Dermatology Department of The Affiliated Hospital of Xuzhou Medical University from January 2017 to January 2019.

Methodology: Patients of either gender and age, clinically diagnosed as seborrheic keratosis, verruca plana, and nevus pigmentosus without any prior treatment, were enrolled. Patients with extremities and trunk involvement were excluded. One typical skin lesion was chosen from each patient and subjected to dermatoscopy and RCM separately; imaging features were recorded and analysed.

Results: A total of 402 patients (183 men and 219 women) between 6 and 88 years of age (mean age 41.8 years) were inducted. The duration of disease was between one week and 10 years. Seborrheic keratosis on dermatoscopy presented as acne-like openings (122/172; 70.93\%, milia-like cysts (113/172; 65.70\%), hairpin-like vessels (108/172; 62.79\%, brain-like structures (103/172; $59.88 \%$, worm-like pharyngeal margins (17/172; $9.88 \%)$, and fingerprint-like structures $(8 / 172 ; 4.65 \%)$. On RCM, it showed epidermal cerebral gyrus structure (165/172; 95.93\%), superficial vasodilatation and hyperemia (81/172; 47.09\%), and keratinous cysts (73/172; 42.44\%). Verruca plana on dermatoscopy showed a number of punctate hemorrhages scattered against a light-red background (108/114; 94.74\%); on RCM it showed rose-like concentric structures (89/114; 78.07\%). The features of nevus pigmentosus observed by dermatoscopy were homogeneous mode $(23 / 52 ; 44.23 \%)$, light brown color $(30 / 52 ; 57.69 \%)$ for intradermal nevus; mesh mode $(18 / 41 ; 43.90 \%$, dark brown color, little black dots and spherical structure (both $18 / 41 ; 43.90 \%)$ were visible for junctional nevus; globular mode, reticular and cobblestone structures (both $11 / 23 ; 47.83 \%$ ) for compound nevus. On RCM, there were a few nevus cells visible within the dermal papilla $(52 / 52 ; 100 \%)$ for intradermal nevus; bright pebble-like structures accumulated in the basal layer, nested round and elliptical nevus cells (40/41; 97.56\%) for junctional nevus; nevus cells in the epidermis and dermis (21/23; $91.30 \%)$ for compound nevus.

Conclusion: Used in combination with clinical manifestations, the application of dermatoscopy and RCM may help distinguish seborrheic keratosis, verruca plana, and nevus pigmentosus on the basis of their respective dermatoscopic and RCM features.
\end{abstract}

Key Words: Dermatoscopy, Reflective confocal microscope, Seborrheic keratosis, Verruca plana, Nevus pigmentosus, Brain-like structures, Rose-like structure.

How to cite this article: Lu Q, Wang S, Wu T, Jiang G. Dermatoscopy and Reflective Confocal Microscopy for Facial Seborrheic Keratosis, Verruca Plana, and Nevus Pigmentosus. J Coll Physicians Surg Pak 2021; 31(04):450-454.

\section{INTRODUCTION}

Seborrheic keratosis occurs mostly in the elderly and increases in size and number with age, presenting as a light brown rash or flat papule, with smooth or slightly papillary surface.

Correspondence to: Dr. Guan Jiang, Department of Dermatology, Affiliated Hospital of Xuzhou Medical University, Xuzhou, China

E-mail:dr.guanjiang@xzhmu.edu.cn

Received: March 06, 2020; Revised: September 12, 2020; Accepted: November 04, 2020

DOI: https://doi.org/10.29271/jcpsp.2021.04.450
Verruca plana is mostly caused by infection with the human papilloma virus types 3 and 10, presenting as flat papules of varying sizes that are lightly raised. The boundary is clear and can be densely distributed or lined up because of local scratching. ${ }^{1}$

Nevus pigmentosus is also known as nevus cell nevus. The elementary damage is usually a spot rash, papule, or nodule measuring $<6 \mathrm{~mm}$ in diameter. ${ }^{2}$

Seborrheic keratosis, verruca plana, and nevus pigmentosus are common skin lesions and seriously affect the aesthetics of patients. A clear diagnosis is important for optimal treatment options, but when these diseases appear on the face, they are often difficult to differentiate. Histopathology examination is 
the gold standard for diagnosis, but it is an invasive examination that cannot be accepted by most patients. Dermatoscopy and RCM function, as non-invasive methods for skin-disease examination, have the advantages of acquiring rapid, real-time and dynamic skin micro-anatomical images, while avoiding invasive trauma from skin biopsy. ${ }^{3-5}$ Dermatoscopy allows doctors to better assess the superficial structure of the epidermis and dermis by attaching the camera to a magnifying glass. ${ }^{6}$ Similarly, RCM can afford observation of the three-dimensional section of the skin.

Dermatoscopy mainly focuses on the observation of structure in superficial pigmented lesions, blood vessels and hairfollicles. But it does not achieve good sensitivity for inspecting deep skin structures and cytomorphological details. ${ }^{6}$ In contrast to dermatoscopy, RCM allows further information regarding the tissue and cell morphology from the superficial layers of the skin down to the superficial reticular dermis. ${ }^{7}$ However, at the aspect of observing structures of superficial skin lesions, RCM is not as intuitive as dermatoscopy. In 2010, Liu reported the value of RCM in the differential diagnosis of seborrheic keratosis and verruca plana, and the characteristic of verruca plana was the rose-like concentric structures. ${ }^{8}$ In 2017, Hui found that combining RCM and dermoscopy can improve the accuracy for clinical diagnosis of verruca plana. ${ }^{1}$

The objective of this study was to describe the features of facial seborrheic keratosis, verruca plana, and nevus pigmentosus by dermatoscopy and reflective confocal microscope (RCM) in order to provide the basis for differential diagnosis of these three facial diseases with two non-invasive diagnostic techniques.

\section{METHODOLOGY}

This observational study was conducted at the Department of Dermatology, the Affiliated Hospital of Xuzhou Medical University from January 2017 to January 2019. Patient clinically diagnosed as seborrheic keratosis, verruca plana, and nevus pigmentosus, without any prior treatment, were enrolled into this study. All patients with facial skin diseases were clinically diagnosed by two attending physicians, only patients with consistent clinical diagnostic results were considered (Figure 1). The inclusion criteria were: all casesconfirmed by two dermatologists with senior professional titles according to the corresponding diagnostic criteria and reached consensus not treated before the examination. The exclusion criteria were: refusal to participate in the study; and patients showing extremities and trunk involvement.

Then the dermatoscopy RCM of those recruited were performed and recorded by one professional, respectively. The images of typical cases were collected. The final data was statistically analysed by a researcher. This study was approved by the local Ethics Committee and the ethical principles of Helsinki Declaration were conducted. Informed consents were obtained from all participants.

A hand-held skin RCM (Vivascopel500 Lucid, USA) was used for scanning. The light source was a laser beam with a wavelength of $830 \mathrm{~nm}$, magnification of the objective lens was $30 x$, and vertical axis image scanning pitch was $5 \mu \mathrm{m}$. Dermoscopic photographs were acquired using a dermatoscope (Beining, Inc., Nanjing, China) attached to a digital camera. The light source is visible light, magnification, and visible area, 20x, and $12 \mathrm{~mm} \times 12 \mathrm{~mm}$, respectively.

They were appropriately positioned after their skin was cleaned. Typical skin lesions were examined with dermatoscopy, and images were collected subsequently. Then the same lesions were cleaned with $75 \%$ medical-grade alcohol, followed by RCM examination. The RCM probe was applied close to and perpendicular to the skin surface. Scanning was performed after the probe was fixed. The skin was scanned layer by layer, and the best cross-sectional images were stored in the computer for further analysis.

Due to the invasiveness of histopathology, among 402 patients with the three facial skin diseases, only 53 (18 seborrheic keratosis, 11 verruca plana, and 24 nevus pigmentosus) were randomly selected for this examination. Biopsies of the lesions at the same site of dermoscopy and RCM examination were performed for histopathologic analysis. The excisions were fixed in formalin and embedded in paraffin. After routine processing, slides were stained with hematoxylin and eosin.

\section{RESULTS}

A total of 402 patients were recruited; they included 183 male and 219 female between 6 and 88 years of age (mean age 41.8 years) clinically diagnosed as seborrheic keratosis, verruca plana, and nevus pigmentosus without any prior treatment. The duration of diseases of 402 patients was between 1 week and 10 years. There were 172 cases of seborrheic keratosis (98 males, 74 females; age $=21$ to 86 years; mean age 58.6 years). The dermatoscopic features included acne-like openings (122/172; 70.93\%), milia-like cysts (113/172; 65.70\%), hairpin-like vessels (108/172; 62.79\%), brain-like structures (103/172; $59.88 \%)$, worm-like pharyngeal margins (17/172; 9.88\%), and fingerprint-like structures (8/172; 4.65\%) (Figure 2A). The RCM features included epidermal cerebral gyrus structure (165/172; $95.93 \%)$, superficial vasodilatation and hyperemia (81/172; $47.09 \%)$, and keratinous cysts (73/172; 42.44\%, Figure 2D). The histopathological features include hyperkeratosis, acanthosis, and papillary hyperplasia(Figure 3A,TableI).

There were 114 cases of verruca plana $\square 48$ males, 66 females; age, 6 to 64 years; mean age $=32.5$ years), whose dermatoscopic and RCM features included a number of punctate hemorrhages scattered in a light-red background (108/114; $94.74 \%)$ and rose-like concentric structures $(89 / 114 ; 78.07 \%)$ present between the granular layer and the upper layer of the spinous layer (Figure 2B, 2E). The histopathological features included obvious hyperkeratosis and acanthosis, vacuolisation of the upperepidermis cells, and obvious mesh-like appearance of the stratum corneum cells due to vacuolis ation (Figure 3B). 
Table I: Dermatoscopy and RCM imaging features and histopathology of the diseases.

\begin{tabular}{|c|c|c|c|c|c|c|}
\hline Diseases & \multicolumn{2}{|c|}{ Number of cases } & \multicolumn{2}{|c|}{ Dermoscopy features } & RCM features & Histopathology features \\
\hline $\begin{array}{l}\text { Seborrheic } \\
\text { keratosis }\end{array}$ & \multicolumn{2}{|l|}{172} & \multicolumn{2}{|c|}{$\begin{array}{l}\text { Acne-like openings, milia-like cysts, } \\
\text { hairpin-like vessels, brain-like } \\
\text { structures, worm-like pharyngeal } \\
\text { margins and fingerprint-like } \\
\text { structures. }\end{array}$} & $\begin{array}{l}\text { Epidermal cerebral gyrus and } \\
\text { keratinous cysts, superficial } \\
\text { vasodilatation and hyperemia. }\end{array}$ & $\begin{array}{l}\text { Hyperkeratosis, acanthosis and } \\
\text { papillary hyperplasia. }\end{array}$ \\
\hline Verruca plana & \multicolumn{2}{|l|}{114} & \multicolumn{2}{|c|}{$\begin{array}{l}\text { A number of punctate hemorrhages } \\
\text { scattered against a light-red } \\
\text { background. }\end{array}$} & $\begin{array}{l}\text { Rose-like concentric structures } \\
\text { present between the granular layer } \\
\text { and the upper layer of the spinous } \\
\text { layer. }\end{array}$ & $\begin{array}{l}\text { Obvious hyperkeratosis and } \\
\text { acanthosis, vacuolization of the } \\
\text { upper epidermis cells, and } \\
\text { stratum corneum cells showing } \\
\text { obvious mesh-like appearance } \\
\text { due to vacuolization. }\end{array}$ \\
\hline \multirow{3}{*}{$\begin{array}{l}\text { Nevus } \\
\text { pigmentosus }\end{array}$} & \multirow{3}{*}{116} & $\begin{array}{l}\text { Intradermal } \\
\text { nevus }\end{array}$ & 52 & $\begin{array}{l}\text { Homogeneous mode, light } \\
\text { brown color. }\end{array}$ & $\begin{array}{l}\text { a few nevus cells were visible } \\
\text { within the dermal papilla. }\end{array}$ & \multirow{3}{*}{$\begin{array}{l}\text { Nevus cells nesting at different } \\
\text { levels of the skin. }\end{array}$} \\
\hline & & $\begin{array}{l}\text { Junctional } \\
\text { nevus }\end{array}$ & 41 & $\begin{array}{l}\text { Mesh mode, dark brown } \\
\text { color, little black dots and } \\
\text { spherical structure were } \\
\text { visible. }\end{array}$ & $\begin{array}{l}\text { Bright pebble-like structures } \\
\text { accumulated in the basal layer, } \\
\text { round and elliptical nevus cells } \\
\text { were nested. }\end{array}$ & \\
\hline & & $\begin{array}{l}\text { Compound } \\
\text { nevus }\end{array}$ & 23 & $\begin{array}{l}\text { Globular mode, reticular } \\
\text { structures and } \\
\text { cobblestone structures. }\end{array}$ & $\begin{array}{l}\text { Nevus cells in the epidermis and } \\
\text { dermis. }\end{array}$ & \\
\hline
\end{tabular}

Table II: Comparison of features of dermatoscopy, RCM, and histopathology.

\begin{tabular}{|c|c|c|c|}
\hline Features & Dermatoscopy & (2) & Histopathology \\
\hline Pain & No & No & Yes \\
\hline Trauma & No & No & Yes \\
\hline Real-time & Yes & Yes & No \\
\hline Dynamic & Yes & Yes & No \\
\hline Degree of difficulty & Simple & Simple & Complexity \\
\hline Diagnostic time & $10 \min$ & $10 \min$ & Hours or days \\
\hline Observation depth & Dermal papilla & Epidermis or superficial dermis & Subcutaneous fat layer \\
\hline
\end{tabular}

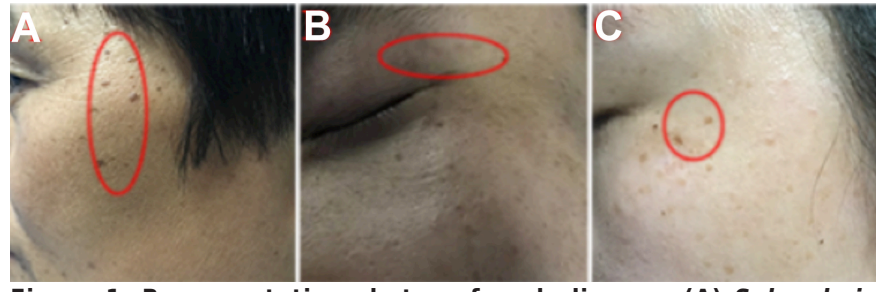

Figure 1. Representative photos of each disease. (A) Seborrheic keratosis: A 49-year woman with dark-brown spots on her face. (B) Verruca plana: A 30-year man with multiple brown pimples in his left upper eyelid. (C) Nevus pigmentosus: A 30-year woman with multiple brown spots on her face.
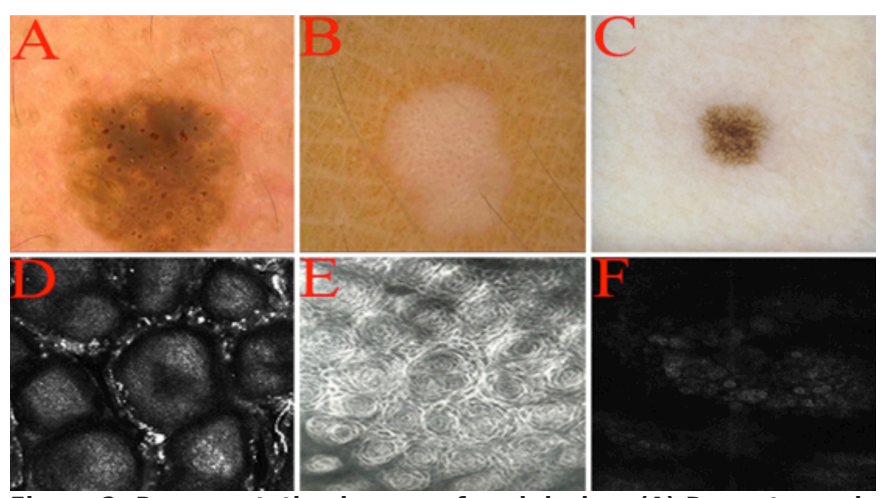

Figure 2: Representative images of each lesion. (A) Dermatoscopic features of seborrheic keratosis: Acne-like opening, fingerprint-like structure, clear edges. (B) Dermatoscopic features of verruca plana: A number of punctate hemorrhages scattered against a light-red background. (C) Dermatoscopic features of nevus pigmentosus: Homogeneous grid mode. (D) RCM features of seborrheic keratosis: Cerebriform surface structures. (E) RCM features of verruca plana: Epidermal rose-like structure. (F) RCM features of nevus pigmentosus: Epidermal and dermal honeycomb structure.

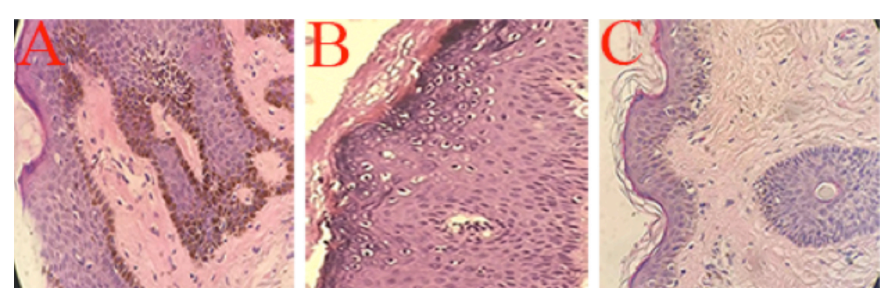

Figure 3: Histopathological pictures of each disease. (A) Seborrheic keratosis: Hyperkeratosis, acanthosis and papillary hyperplasia. (B) Verruca plana: Hyperkeratosis and acanthosis, vacuolar cell of the upper epidermis. (C) Nevus pigmentosus: Nevus cells nesting in the dermis.

The dermatoscopic features of 116 patients with nevus pigmentosus ( 37 males, 79 females; age, 9 to 74 years; mean age $=25.9$ years) with nevus pigmentosus were subdivided into three further groups. These 52 cases of intradermal nevus: homogeneous mode (23/52; 44.23\%), light brown color $(30 / 52 ; 57.69 \%) ; 41$ cases of junctional nevus: mesh mode $(18 / 41 ; 43.90 \%)$, dark brown color, little black dots and spherical structure (both $18 / 41 ; 43.90 \%$ ) and 23 cases of compound nevus: globular mode, reticular and cobblestone structures (both $11 / 23 ; 47.83 \%$, Figure $2 \mathrm{C}$ ). The RCM features of nevus pigmentosus showed a few nevus cells were visible within the dermal papilla $(52 / 52 ; 100 \%)$ for intradermal nevus; bright pebble-like structures accumulated in the basal layer, with nested round and elliptical nevus cells $(40 / 41 ; 97.56 \%)$ for junctional nevus; and nevus cells in the epidermis and dermis (21/23; 91.30\%) for compound nevus (Figure 2F). The histopathological features included nevus cells nested at different levels of the skin (Figure 3C). 


\section{DISCUSSION}

Dermatopathology has been developed for more than two centuries and is considered as the 'gold standard' in the diagnosis of many skin diseases. However, biopsy is generally invasive, with injuries, pain and scars, which may decrease the compliance of the patients. Clinically, noninvasive methods are urgently required, especially in the diagnosis of lesions in an exposal area. ${ }^{9}$ As a skin microscope, dermatoscopy can magnify the skin by means of oil-immersed or polarised light allowing in vivo examination of skin microstructures from the epidermis to the superficial dermis that are invisible to the naked eye. ${ }^{10}$ RCM is a real-time dynamic scanning imaging technology, which uses the different refractive indices of cells and tissues to convert the reflected light generated by laser excitation into images through a computer. ${ }^{11,12}$ Since dermatoscopy and RCM can repeat the examination of the same skin area without causing any damage, they can effectively monitor disease progression. ${ }^{13,14}$

Seborrheic keratosis, whose appearance is generally a small roundish reddish to brownish scaling lesion ranging in size from a few $\mathrm{mm}$ to many $\mathrm{mm}$, may have a single presentation or be one of many such lesions. It is a commonly encountered lesion on the face, trunk, or extremities. Clinically, some skin diseases, such as verruca plana and nevus pigmentosus can be very similar to seborrheic keratosis and the differential diagnosis between them is often challenging to dermatologists. ${ }^{15}$ In this study, however, we have observed that the dermoscopic features of seborrheic keratosis are sharply demarcated borders, milia-like cysts, acne-like openings, brain-like structures and hairpin blood vessels. The RCM features included epidermal cerebral gyrus and keratinous cysts, superficial vasodilatation, and hyperemia favour a diagnosis of seborrheic keratosis. The main RCM feature of rose-like concentric structures had highly specific for verruca plana without treatment, which may valuable in the diagnosis of verruca plana. The nevus cells are arranged in a round or elliptical nest with high refraction, or agglomerate in the dermis, which are the features of nevus pigmentosus that can be observed under RCM.

The features of the diseases on dermatoscopy and RCM remain highly consistent with histopathological changes. For example, seborrheic keratosis on RCM shows epidermal cerebral gyrus structure that corresponds to histopathological papillomatosis. ${ }^{16}$ Seborrheic keratosis on dermatoscopy shows brain-like structures correspond to histopathological acanthosis. ${ }^{17}$ Cruca plana on RCM shows rose-like concentric structures correspond to histopathological koilocyte. Nevus pigmentosus on RCM shows high-refractive pigment masses correspond to histopathological nevus cell masses, ${ }^{18}$ Nevus pigmentosus on dermatoscopy shows reticular structures correspond to histopathological melanocytes of epidermal process (Table I).

Compared with histopathology, dermatoscopy and RCM have many advantages: (a) examination is painless; (b) there is no damage to skin or risk of metastasis of skin lesions; (c) the normal morphology and physiological functions of cells and tissues is preserved; (d) fast acquisition of real-time, dynamic microanatomical images of the skin is possible $\square$ and (e) multiple examinations can be performed at the same site (Table II). ${ }^{19-22}$

This study still has some limitations, for the sample size was small and not all patients were biopsied. The age and the duration of disease was very wide. Patients were reluctant to submit to biopsy of lesions in an exposal body part because of the risk of scarring. Further study with large samples may be required to verify the feasibility of dermatoscopy and RCM in disease diagnosis.

\section{CONCLUSION}

Used in combination with clinical manifestations, the application of dermatoscopy and RCM may help distinguish seborrheic keratosis, verruca plana, and nevus pigmentosus on the basis of their respective dermatoscopic and RCM features.

\section{ACKNOWLEDGMENT:}

The research was supported by the Youth Medical Science and Technology Innovation Project of Xuzhou City (No.XWKYHT20200011)

\section{ETHICAL APPROVAL:}

Ethical approvals were obtained prior to initiation of the research work.

\section{PATIENTS' CONSENT:}

Informed consents were obtained from all patients to publish the data concerning this case.

\section{CONFLICT OF INTEREST:}

The authors declared no conflict of interest.

\section{AUTHORS' CONTRIBUTION:}

QL, GJ: Conceived and designed the experiment.

SW: Analysed the data.

TW: Performed the experiments.

\section{REFERENCES}

1. Hui D, HongYan J, Ai E X. Evaluation of verruca plana by in vivo reflectance confocal microscopy and dermoscopy. Skin Res Technol 2017; 23:437-40. doi: 10.1111/srt.12336. 
2. Kim JK, Nelson KC. Dermoscopic features of common nevi: A review. G Ital Dermatol Venereol 2012; 147:141-8.

3. Ilie MA, Caruntu C, Lupu M, Lixandru D, Tampa M, Georgescu $\mathrm{SR}$, et al. Current and future applications of confocal laser scanning microscopy imaging in skin oncology. Oncol Lett 2019; 17:4102-11. doi: 10.3892/ ol.2019.10066.

4. Cinotti E, Galluccio D, Tognetti L, Habougit C, Manganoni $A M$, Venturini $M$, et al. Nipple and areola lesions: review of dermoscopy and reflectance confocal microscopy features. J Eur Acad Dermatol Venereol 2019; 33:1837-46. doi: 10.1111/jdv.15727.

5. Ma J, Zhang X, Lv Y, Zhao C, Li Q, Yang X, et al. Clinical application of confocal laser scanning microscopy for atypical dermatoses. Cell Biochem Biophys 2015; 73:199-204. doi: 10.1007/s12013-015-0625-5.

6. Eftekhari H, Azimi SZ, Rafiei R, Darjani A, Alizadeh N, Rafiei $E$, et al. Dermoscopic features of lichen planopilaris in Northern Iran: A prospective observational study. Int J Dermatol 2019; 58:1406-14. doi: 10.1111/ijd.14589.

7. Hirokawa D, Lee JB. Dermatoscopy: an overview of subsurface morphology. Clin Dermatol 2011; 29(5):557-65. doi: 10.1016/j.clindermatol.2010.12.002.

8. Gruber MJ, Wackernagel A, Richtig E, Koller S, Smolle J. Digital image enhancement for in vivo laser scanning microscopy. Skin Res Technol 2010; 11(4):248-253. doi: 10.1111/j.0909-725X.2005.00128.x.

9. Liu H, Chen S, Zhang F, Shi B, Shi Z, Zhang D, et al. Seborrheic keratosis or verruca plana? A pilot study with confocal laser scanning microscopy. Skin Res Technol 2010; 16(4):408-12.

10. Bayraktar M, Kockara S, Halic T, Mete M, Wong HK, Iqbal K. Local edge-enhanced active contour for accurate skin lesion border detection. BMC Bioinformatics 2019; 20 (Suppl 2):91. doi: 10.1186/s12859-019-2625-8.

11. González S, Gilaberte-Calzada Y. In vivo reflectance-mode confocal microscopy in clinical dermatology and cosmetology. Int J Cosmet Sci 2008; 30:1-17. doi: 10.1111/j.1468-2494.2008.00406.x.

12. Longo C, Ragazzi M, Rajadhyaksha M, Nehal K, Bennassar A, Pellacani G, et al. In Vivo and Ex Vivo Confocal Microscopy for Dermatologic and Mohs Surgeons. Dermatol Clin 2016; 34:497-504. doi: 10.1016/j.det.2016.05.012.
13. Koehler MJ, Speicher M, Lange-Asschenfeldt S, Stockfleth E, Metz S, Elsner $\mathrm{P}$, et al. Clinical application of multiphoton tomography in combination with confocal laser scanning microscopy for in vivo evaluation of skin diseases. Exp Dermatol 2011; 20:589-94. doi: 10.1111/j.1600-0625. 2011.01279.x.

14. Eşme P, Gür Aksoy G, Elçin G. No additional benefit of combining fractional carbon dioxide laser with narrow-band ultraviolet $b$ phototherapy for vitiligo: A randomised prospective study with half-body side comparison. Dermatol Surg 2019; 45:1627-34. doi: 10.1097/DSS.00000000000 01890.

15. Karadag AS, Parish LC, The status of the seborrheic keratosis. Clin Dermatol 2018; 36: 275-7. doi: 10.1016/ j.clindermatol.2017.09.011.

16. Guo A, Chen J, Yang C, Ding Y, Zeng Q, Tan L. The challenge of diagnosing seborrheic keratosis by reflectance confocal microscopy. Skin Res Technol 2018; 24:663-6. doi: 10.1111/srt.12582.

17. Minagawa A. Dermoscopy-pathology relationship in seborrheic keratosis. J Dermatol 2017; 44:518-524. doi: 10.1111/1346-8138.13657.

18. Laimer M, Arzberger E, Kirchner CA, Prodinger C, Hofmann WR, Ahlgrimm SV. Noninvasive rcm for differentiation of melanotic macules from melanocytic lesions-blinded evaluation of a series of 42 pigmented macules. Dermatol Surg 2017; 43: 911-9. doi: 10.1097/DSS.000000000000 1110.

19. Hartmann D, Ruini C, Mathemeier L, Bachmann MR, Dietrich A, Ruzicka $T$, et al. Identification of ex-vivo confocal laser scanning microscopic features of melanocytic lesions and their histological correlates. J Biophotonics 2017; 10:128-42. doi: 10.1002/jbio.201500335.

20. Gadjiko M, Rossi AM. Ex vivo confocal microscopy: A diagnostic tool for skin malignancies. Cutis 2017; 100:81-3.

21. Lu Q, Yang C, Wu J, Wei Z, Xu S, Wang C, et al. Confocal laser scanning microscopy, a diagnostic alternative for five pigmented lesions on the face: An observational study. Skin Res Technol 2019; 25:871-6. doi: 10.1111/srt.12749.

22. Micali G, Verzì $A E$, Lacarrubba $F$. Alternative uses of dermoscopy in daily clinical practice: An update. J Am Acad Dermatol 2018; 79:1117-32. doi: 10.1016/j.jaad.2018. 06.021 . 